\title{
Numerical exploration of mixing and combustion in a dual-mode combustor with backward-facing steps
}

\author{
Wei Huang*, Lang-quan Li, Li Yan`, Lei Liao \\ Science and Technology on Scramjet Laboratory, National University of Defense Technology, Changsha, Hunan \\ 410073, People's Republic of China
}

\begin{abstract}
Dual-mode scramjet combustor is the crucial component for the combined cycle engine of space mission vehicles. The Reynolds Averaged Navier-Stokes (RANS) equations, Spalart-Allmaras turbulence model and the finite-rate reaction model have been utilized to investigate the mixing and combustion in a dual-mode combustor with backward-facing steps, and the species distributions and the Mach number profile of a turbulent diffusion combustion problem have been employed to validate the numerical approach. Moreover, the influences of the injection strategy and the fuel equivalence ratio arrangement on its mixing and combustion flow fields have been explored. The obtained results show that the vertical injection is beneficial for mode transition, and an obvious high pressure region is generated with the vertical injection strategy. Accordingly, its mass-weighted average Mach number drops more sharply. The lower total equivalence ratio is beneficial for the mixing augmentation, as well the smaller fuel equivalence ratio discrepancy. However, the larger total equivalence ratio is beneficial for the mode transition.
\end{abstract}

Keywords: Mode transition; dual-mode combustor; backward-facing step; supersonic flow; mixing; combustion

\section{Introduction}

Dual-mode combustor, as one of the most important component for the engineering implementation of the combined cycle engine of space mission vehicles [1], has attracted a great deal of attention, and a number of

\footnotetext{
* Associate Professor, Corresponding author, Email: gladrain2001@ 163.com, Phone: +86 731 84576447, Fax: +86 73184512301

$\dagger$ Associate Professor, Corresponding author, Email: scarlet@163.com, Phone: +86 731 84576452, Fax: +86 73184512301 
studies have investigated the combustion mode transition under the supersonic state using different flameholding devices since the adequate mixing and combustion between the fuel and air must take place at a time scale of the order of milliseconds [2][3], such as the strut [4][5] the backward-facing step [6][7], aeroramp [8], wall mounted cavity [9], and the combinational strategies [10][11][12]. Zhang et al. [13] investigated the nonlinear characteristics in the combustion mode transition and proposed a pressure-magnitude-based approach to detect the combustion modes experimentally.

From the view of the theoretical analysis, a mechanical approach was developed by Cui et al. [14] to investigate the nonlinear behavior of mode transition under the assumption of inviscid flow, and the hysteresis phenomenon of mode transition was identified. Finally, the topological rule that governs the hysteresis phenomenon was discovered as well. Torrez et al. [14] expanded the simple Shapiro method to create a new approach that includes finite-rate chemistry and high-temperature gas properties to compute the thrust of a dual-mode scramjet, and the improved approach was validated for both ram-mode and scram-mode operations. Recently, Hao et al. [16] proposed a method of modeling for the mode transition logic between the three operation modes, namely scramjet mode, ramjet mode and unstarted mode, and the previous analytical model were corrected to fulfill the logical integrity. This framework provides a foundation in the perspective of system integrated for airframe, propulsion and control.

Kobayashi et al. [17] examined a scramjet combustor with single and two kinds of two-stage fuel injection to determine whether it could be operated in the ramjet mode, and one-dimensional calculation was utilized to interpret the experimental data. A supersonic combustor with several combustor lengths, total temperatures and equivalence ratios was tested in a directly connected wind tunnel, and four combustion modes were observed, namely nonignition, weak combustion, supersonic combustion and dual-mode combustion. These combustion modes are related to combustion length and total temperature [18]. 
However, to the best of the authors' knowledge, as a crucial and efficient tool to cut the expensive cost in the experimental or flight test and support the results obtained by the theoretical analysis, the computational fluid dynamic approach has been widely employed to explore the flow field information in the airbreathing propulsive system firstly and comprehensively. In the open literature, there are only a few researches on the dual-mode combustor on the view of numerical simulation, especially on the influence of the fuel equivalence ratio on the mode transition mechanism, and this is a crucial step for the engineering design of the combined cycle engine for the space vehicle.

For more in-depth understanding the mean flow field properties in the dual-mode scramjet combustor, the objective of this paper is to investigate the influence of the injection strategy and the fuel equivalence ratio arrangement on the mixing and combustion in a dual-mode combustor with backward-facing steps, and the total equivalence ratio is set to be $0.7,1.0,1.2$ and 1.6 by adjusting the jet pressure. The mixing efficiency is utilized to evaluate the effect of the fuel equivalence ratio arrangement on the flow field properties quantitatively. In the current study, the effect of the sidewall on the mixing and combustion of the dual-mode combustor has not been considered, and this would be conducted and compared with the conclusion obtained in this paper in the near future. In other words, the three-dimensional simulation is out of the scope in this paper.

\section{Physical model}

The geometric model employed in the current study is based on a typical dual-mode scramjet combustor investigated previously by Wang and Wu [19], see Fig.1, and Huang et al.[6] studied the influence of the pressure and temperature of the fuel injection on the mode transition and the movement of the shock-wave train further. Fig.1 depicts the schematic diagram of a dual-mode combustor with backward-facing steps, and it consists an isolator, a constant-area combustor, a divergent combustor and a nozzle. The position $x=0$ is at the 
entrance of the combustor. The length and height of the isolator are $200 \mathrm{~mm}$ and $18 \mathrm{~mm}$, respectively. The isolator ends in a small step both on the top and bottom walls, and the height of the step is $3 \mathrm{~mm}$. Downstream of the step is a constant-area combustor section of $80 \mathrm{~mm}$. From $x=80 \mathrm{~mm}$ on, the upper wall of the combustor diverges with a constant angle of $3^{\circ}$ to compensate for the boundary layer growth and avoid large amplitude oscillations of a starting shock wave [20], and its length is $300 \mathrm{~mm}$. Downstream of the divergent combustor, there is a nozzle with its length being $161.5 \mathrm{~mm}$, and it diverges $17.5^{\circ}$ both on the top and bottom walls, see Fig.1.

For a number of reasons, hydrogen is often considered as the fuel for scramjets for hypersonic vehicles [21]. Therefore, the fuel is set to be hydrogen in this paper, and it can be injected horizontally from the center of the backward-facing steps with local sonic velocity, namely $T_{1}$ and $T_{2}$, or vertically $95 \mathrm{~mm}$ downstream of the entrance of the constant-area combustor, namely $T_{3}$ and $T_{4}$, see Fig.1. Huang and Yan [22] provided a detailed review on the research progress in transverse injection flow fields, and two additional important topics were included in another survey [23], namely interaction between jet and vortex generator and interaction between jet and shock wave. To reduce the computational time as much as possible, but still retaining all relevant physics of the scramjet combustor the computational configuration is simplified in the sense that all the meshing, modeling, and computational analyses are done in 2D [24]. The width of the injection slot is $0.25 \mathrm{~mm}$.

The air flows from left to right with the Mach number being 2.05, the static pressure being $341 \mathrm{kPa}$ and the static temperature being $1172 \mathrm{~K}$. The total temperature of the fuel is fixed to be $300 \mathrm{~K}$, and this is the same as the wall temperatures. The static pressure of the fuel is varied in order to investigate the influence of the fuel equivalence ratio arrangement on the mixing and combustion flow field of the dual-mode combustor, and the total equivalence ratio is set to be $0.7,1.0,1.2$ and 1.6. 


\section{Numerical approach}

In the present case, all of the 2D models are generated using the available commercial software Gambit, and computational analysis are done by using FLUENT [25]. The grid is densely clustered near the walls of the combustor and in the vicinity of the injection slot, and the height of the first row of cells is set at a distance to the wallof $0.001 \mathrm{~mm}$, which results in a value of wall $y^{+}$smaller than 15.0 for all of the flow field.

The Reynolds Averaged Navier-Stokes (RANS) equations are solved with the density based (coupled) double precision solver by using a finite-volume integration scheme, and the second order spatially accurate upwind scheme (SOU) with the advection upstream splitting method (AUSM) flux vector splitting is used. The Courant-Friedrichs-Lewy number defined as $|u| \Delta t / \Delta l$ is ramped from 0.1 to 2.0 over the initial 100 steps, where $u, \Delta t$ and $\Delta l$ are the velocity, time and spatial steps respectively. The Spalart-Allmaras turbulence model and the finite-rate reaction model are employed to simulate the combustion flow field in the dual-mode combustor. The Spalart-Allmaras turbulence model is chosen for it gives good results for boundary layers subjected to adverse pressure gradients [26]. Further, this model is designed specifically for aerospace applications involving wall-boundary flows. The finite-rate reaction model is selected for it is acceptable for combustion with relatively slow chemistry and small turbulent fluctuations, i.e. supersonic flames. The modified turbulent viscosity and the turbulent intensity are set to be $0.001 \mathrm{~m}^{2} / \mathrm{s}$ and $0.1 \%$ respectively, and the turbulent viscosity ratio is 10 . The turbulent Schmidt and Prandtl numbers are fixed to be 0.7 and 0.85 respectively.

Kumaran and Babu [27] found that multi-step chemistry model predict higher and more extensive spread heat discharge than what is anticipated by single step chemistry model. The single step chemistry model is proved to be fit for foreseeing the general execution parameters with impressively less computational expense [28][29][30]. Therefore, in the current study, the single step chemistry model is used instead of the multi-step chemistry model. 
The molecular formula of the hydrocarbon is assumed to be $C_{x} H_{y}$, and the supersonic freestream is composed of $21 \% \mathrm{O}_{2}$ and $79 \% \quad \mathrm{~N}_{2}$. Then, the chemical reaction equation for the hydrocarbon is

$$
C_{x} H_{y}+\left(x+\frac{y}{4}\right)\left(O_{2}+\frac{79}{21} N_{2}\right) \rightarrow x \mathrm{CO}_{2}+\frac{y}{2} H_{2} O+\frac{79}{21}\left(x+\frac{y}{4}\right) N_{2}
$$

The stoichiometric ratio for the hydrocarbon and air is defined as,

$$
f_{s t}=\frac{W_{C_{x} H y}}{\left(x+\frac{y}{4}\right)\left(W_{O_{2}}+\frac{79}{21} W_{N_{2}}\right)}=\frac{36 x+3 y}{103(4 x+y)}
$$

Herein, $W_{i}$ is the molecular weight of species $i$. The equivalence ratio of the hydrocarbon $(\varphi)$ is defined as,

$$
\varphi=\frac{f}{f_{s t}}=\frac{\dot{m}_{f} / \dot{m}_{\infty}}{f_{s t}}
$$

Herein, $\dot{m}_{\infty}$ and $\dot{m}_{f}$ are the mass flow rates of supersonic freestream and fuel respectively.

If $x=0$ and $y=2$, we can obtain the stoichiometric ratio for the hydrogen and air.

$$
f_{H_{2}, S t}=\frac{36 x+3 y}{103(4 x+y)}=\frac{3}{103}=0.0291
$$

While no-slip conditions are applied along the solid walls by setting the velocity components to zero and nullifying the energy contributions of the wall faces to the dissipative fluxes. Due to the flow being supersonic at the outflow then all the physical variables are extrapolated from the internal cells. The solutions can be considered as converged when most of the residuals reach their minimum values after falling for more than three orders of magnitude, and the computed inflow and the outflow mass flux is required to drop below $0.001 \mathrm{~kg} / \mathrm{s}$

\section{Code validation}

In this section, the experimental model, as studied by Marshall and Kurkov [31], is employed to provide data for validation of the numerical approach. The experimental cases of Marshall and Kurkov [31] are of great value for they provide good spatial resolution of the species distribution, and this model is nearly two-dimensional. Fig.2 shows the mole fraction profiles for different components at the exit of the combustor under the 
combustion condition, as well as the Mach number profile, and it is clearly obvious that the numerical results show very good agreement with the experimental data. At the same time, the intense interaction between jet and supersonic flow was validated by the experimental data previously, and the readers can refer to Ref.[32]. In Ref.[32], the influence of the turbulence model on the simulation of the two-dimensional transverse injection flow field was evaluated, and this provides detailed information for the choice of the numerical approach. In 2013, Pudsey and his coworkers [33] investigated the effect of turbulence model for three-dimensional high-speed transverse jet-interaction simulation. The previous studies have proved that the RANS equations coupled with the Spalart-Allmaras turbulence model can predict the parametric distributions along the bottom wall reasonably, as well as the flow field structures. This may imply that the numerical approach employed is with confident to conduct the following investigation.

\section{Results and discussion}

Fig.3 shows the static pressure contour comparison for different injection strategies, and the fuel equivalence ratio for each injector is 0.35 . It is observed that there is an obvious high pressure region generated when the hydrogen is injected simultaneously at the locations of $T_{3}$ and $T_{4}$, see Fig.3(b), and the combustion occurs more intensively when the vertical injection strategy is employed. This may imply that the mode transition phenomenon takes place more easily with the vertical injection strategy. To probe into the underlying physics, the streamwise progression of the mass-weighted average Mach number is calculated and plotted in Fig.4 from the slice data of the flowfields evaluated at each streamwise station with an increment of $\Delta x=20 \mathrm{~mm}$. It is obvious that the mass-weighted average Mach number drops more sharply at the location $x=0.06-0.1 \mathrm{~m}$ when the hydrogen is injected from $T_{3}$ and $T_{4}$, and it climbs up with the expansion of the nozzle. Its minimum value is below 1.5. However, the mass-weighted average Mach number increases nearly steeply when the hydrogen is 
injected horizontally, namely at the locations of $T_{1}$ and $T_{2}$. Therefore, in the following discussion, the injection strategy with $T_{3}$ and $T_{4}$ has been utilized.

Table.1 depicts the arrangement of fuel equivalence ratio for $T_{3}$ and $T_{4}$, and the total equivalence ratio is set to be 1.0, 1.2 and 1.6. Fig.5 represents the static pressure contour comparison for different fuel equivalence ratio arrangements, and the combustion takes place more intensively with the increase of the total equivalence ratio. When the total equivalence ratio is 1.6, namely Case 6 considered in the current study, the high pressure region is pushed forward to the exit of the isolator, see Fig.5(f). The isolator is used to avoid the high back pressure effect on the inlet performance [34]. If the total equivalence ratio is large enough, the pseudo shock wave would be formed in the isolator, and the subsonic combustion may occur. Due to the asymmetry of the physical model considered in this paper, the flow field is not symmetrical as well, and the combustion near the upper wall occurs more intensively, see Figs.5(a), (c), (d), (e) and (f). However, if the fuel equivalence ratios for $T_{3}$ and $T_{4}$ are set to be 0.8 and 0.2 respectively, namely Case 2 , the flow field becomes symmetrical, and this may imply that more fuel injected can compensate for the boundary layer growth.

To probe into the underlying physics, the streamwise progression of the mass-weighted average Mach number is calculated and plotted in Fig.6 from the slice data of the flowfields evaluated at each streamwise station with an increment of $\Delta x=20 \mathrm{~mm}$, as well as the enlarged view shown in Fig.7. It is observed in Fig.6 that the variable trends of the mass-weighted average Mach number distribution for all cases considered are nearly the same, especially after $x=0.2 \mathrm{~m}$, and the combustion takes place nearly on the subsonic mode when the total equivalence ratio is 1.6 for its lowest mass-weighted average Mach number is 0.997 , namely Case 6 . The high total equivalence ratio is beneficial for the mode transition, see Fig.7, as well as the asymmetrical flow field. This phenomenon is consistent with that observed experimentally by Turner and Smart [35].

In order to explore the flow field properties in Case 6, Fig.8 depicts its parametric contours and streamline 
distribution, and it is shown that there is only a narrow channel for supersonic flow, see Fig.8(a). The narrowest region is located between $x=0.08 \mathrm{~m}$ and $x=0.1 \mathrm{~m}$, and this is consistent with the mass-weighted average Mach number distribution observed in Fig.7. At the same time, the hydrogen near the lower wall penetrates into the core flow deeply, see Fig.8(c), as well as the penetration depth of $\mathrm{H}_{2} \mathrm{O}$, see Fig.8(d). This is due to the reparation of the divergence angle on the upper wall. Further, it is obvious that the recirculation zone formed upstream of the injector on the lower wall is much larger, see Fig.8(e), and there are two large vortexes upstream of the injector on the lower wall. The separation region upstream of the injector is merged with the recirculation zone just downstream of the backward-facing step. However, there is only a small vortex generated on the upper wall visually.

The mixing efficiency is employed to evaluate the flow field performance of the dual-mode combustor, and its definition is as follows [36].

$$
\eta_{m}=\frac{\dot{m}_{\text {fuel, } \text { mixed }}}{\dot{m}_{\text {fuel,total }}}=\frac{\int \alpha_{\text {react }} \rho u d A}{\int f_{H_{2}} \rho u d A}
$$

Herein,

$$
\alpha_{\text {react }}=\left\{\begin{array}{c}
f_{\mathrm{H}_{2}}, f_{\mathrm{H}_{2}} \leq f_{\mathrm{H}_{2}, s t} \\
f_{\mathrm{H}_{2}}\left(1-f_{\mathrm{H}_{2}}\right) /\left(1-f_{\mathrm{H}_{2}, s t}\right), f_{\mathrm{H}_{2}}>f_{\mathrm{H}_{2}, s t}
\end{array}\right.
$$

$f_{\mathrm{H}_{2}}$ is injectant mass fraction, $\alpha_{\text {react }}$ is the injectant fraction mixed in a proportion that can react, $f_{H_{2}, s t}$ is the injectant stoichiometric mass fraction, and its value is 0.0291 for hydrogen. $\dot{m}_{\text {fuel,mixed }}$ is the mixed injectant mass flow, and $\dot{m}_{f u e l, t o t a l}$ is the total injectant flow rate. $\rho$ and $u$ are the local density and velocity respectively, and $A$ is the cross section of the axial station where mixing is evaluated.

Fig.9 represents the mixing efficiency comparison for different injection strategies, and it is observed that the horizontal injection strategy is beneficial for the mixing augmentation. This is because that the mixing process takes place earlier with the horizontal injection strategy, and the mixing efficiency is above 0.9 even at $x=0.1 \mathrm{~m}$. Fig.10 depicts the mixing efficiency comparison for different fuel equivalence ratio arrangement, and it is 
observed that the lower total equivalence ratio is beneficial for the mixing efficiency. The low total equivalence ratio means the low jet-to-crossflow pressure ratio. This conclusion is consistent with that stated in Ref.[32][37]. Further, the mixing efficiency decrease with the increase of the fuel equivalence ratio discrepancy between the injectors, and the same value of the fuel equivalence ratio for the injectors is beneficial for the mixing process between air and injectant in supersonic flow.

\section{Conclusions}

In the current study, a dual-mode scramjet combustor with backward-facing steps has been investigated numerically by the Reynolds Averaged Navier-Stokes (RANS) equations, Spalart-Allmaras turbulence model and the finite-rate reaction model, and a turbulent diffusion combustion problem studied by Marshall and Kurkov [31] has been employed to validate the numerical approach. Further, the influences of the injection strategy and the fuel equivalence ratio on the mixing and combustion in the dual-mode combustor have been explored. We have come to the following conclusions:

- Because the mixing process takes place earlier with the horizontal injection strategy, and the mixing efficiency is higher accordingly. Its value is above 0.9 even at $x=0.1 \mathrm{~m}$. At the same time, an obvious high pressure region is generated with the vertical injection strategy, and its mass-weighted average Mach number drops more sharply. This implies that the vertical injection is beneficial for mode transition.

- The lower total equivalence ratio is beneficial for the mixing augmentation, as well the smaller fuel equivalence ratio discrepancy. However, the larger total equivalence ratio is beneficial for the mode transition, and the combustion takes place nearly on the subsonic mode when the total equivalence ratio is 1.6 . 


\section{Acknowledgements}

The authors would like to express their thanks for the support from the National Science Foundation of China (No.11502291) and a fund for owner of Outstanding Doctoral Dissertation from the Ministry of Education of China (No.201460). Also, the authors thank the anonymous reviewers for some very critical and constructive recommendations on this article.

\section{References}

[1]. Huang W, Yan L, Tan J G. Survey on the mode transition technique in combined cycle propulsion systems. Aerospace Science and Technology, 2014, 39: 685-691

[2]. Vishwakarma M, Vaidyanathan A. Experimental study of mixing enhancement using pylon in supersonic flow. Acta Astronautica, 2016, 118: 21-32

[3]. Huang Z W, He G Q, Qin F, Wei X G. Large eddy simulation of flame structure and combustion mode in a hydrogen fueled supersonic combustor. International Journal of Hydrogen Energy, 2015, 40: 9815-9824

[4]. Bao W, Yang Q, Chang J, Zong Y, Hu J. Dynamic characteristics of combustion mode transitions in a strut-based scramjet combustor model. Journal of Propulsion and Power, 2013, 29(5): 1244-1248

[5]. Yang Q, Chetehouna K, Gascoin N, Bao W. Experimental study on combustion modes and thrust performance of a staged-combustor of the scramjet with dual-strut. Acta Astronautica, 2016, 122, 28-34

[6]. Huang W, Ma L, Pourkashanian M, Ingham D B, Luo S B, Liu J, Wang Z G. Flow-field analysis of a typical hydrogen-fueled dual-mode scramjet combustor. Journal of Aerospace Engineering, 2012, 25: $336-346$ 
[7]. Huang W, Jin L, Yan L, Tan J G. Influence of jet-to-crossflow pressure ratio on nonreacting and reacting processes in a scramjet combustor with backward-facing steps. International Journal of Hydrogen Energy, 2014, 39: 21242-21250

[8]. Bonanos A M, Schetz J A, O'Brien W F, Goyne C P. Dual-mode combustion experiments with an integrated aeroramp-injector/plasma-torch igniter. Journal of Propulsion and Power, 2008, 24(2): 267-273

[9]. Fotia M L, Driscoll J F. Ram-scram transition and flame/shock-train interactions in a model scramjet experiment. Journal of Propulsion and Power, 2013, 29(1): 261-273

[10]. Tian Y, Xiao B, Zhang S, Xing J. Experimental and computational study on combustion performance of a kerosene fueled dual-mode scramjet engine. Aerospace Science and Technology, 2015, 46: 451-458

[11].Xiao B, Xing J, Tian Y, Wang X. Experimental and numerical investigations of combustion mode transition in a direct-connect scramjet combustor. Aerospace Science and Technology, 2015, 46: 331-338

[12].Huang W, Yan L. Numerical investigation on the ram-scram transition mechanism in a strut-based dual-mode scramjet combustor. International Journal of Hydrogen Energy, 2016, 41: 4799-4807

[13].Zhang C, Yang Q, Chang J, Tang J, Bao W. Nonlinear characteristics and detection of combustion modes for a hydrocarbon fueled scramjet. Acta Astronautica, 2015, 110: 89-98

[14].Cui T, Tang S, Zhang C, Yu D. Hysteresis phenomenon of mode transition in ramjet engines and its topological rule. Journal of Propulsion and Power, 2012, 28(6): 1277-1284

[15]. Torrez S M, Dalle D J, Driscoll J F. New method for computing performance of choked reacting flows and ram-to-scram transition. Journal of Propulsion and Power, 2013, 29(2): 433-445

[16]. Hao X, Chang J, Bao W, Zhang Z. A model of mode transition logic in dual-mode scramjet engines. Aerospace Science and Technology, in press, doi: 10.1016/j.ast.2015.12.001

[17].Kobayashi K, Tomioka S, Kato K, Murakami A, Kudo K. Performance of a dual-mode combustor with 
multistaged fuel injection. Journal of Propulsion and Power, 2006, 22(3): 518-526

[18].Masumoto R, Tomioka S, Kudo K, Murakami A, Kato K, Yamasaki H. Experimental study on combustion modes in a supersonic combustor. Journal of Propulsion and Power, 2011, 27(2): 346-355

[19]. Wang J F, Wu Y Z. Numerical analysis for reacting flows in typical three-dimensional supersonic combustor (in Chinese). J. Nanjing Univ. Aeronaut. Astronaut., 2008, 40(3): 308-312

[20]. Kuniyoshi N, Yaga M, Koda A, Teruya I, Ishikawa M. Experimental study of interaction between supersonic duct flow and jets surrounded by the porous cavity. Experimental Thermal and Fluid Science, 2012, 40: 185-194

[21].Huang W, Pourkashanian M, Ma L, Ingham D B, Luo S B, Wang Z G. Effect of geometric parameters on the drag of the cavity flameholder based on the variance analysis method. Aerospace Science and Technology, 2012, 21: 24-30

[22].Huang W, Yan L. Progress in research on mixing techniques for transverse injection flow fields in supersonic crossflows. Journal of Zhejiang University - Science A (Applied Physics \& Engineering), 2013, 14(8): 554-564

[23].Huang W. Transverse jet in supersonic crossflows. Aerospace Science and Technology, 2016, 50: 183-195

[24].Pandey K M, Roga S, Choubey G. Computational analysis of hypersonic combustor using strut injector at flight Mach 7. Combustion Science and Technology, 2015, 187: 1392-1407

[25].Fluent Inc. Fluent 6.3 user's guide, Lebanon, NH, Fluent Inc., 2006

[26].Pudsey A S, Boyce R R, Wheatley V. Influence of common modeling choices for high-speed transverse jet-interaction simulations. Journal of Propulsion and Power, 2013, 29(5): 1076-1086

[27]. Kumaran K, Babu V. Investigation of the effect of chemistry models on the numerical predictions of the supersonic combustion of hydrogen. Combustion and Flame, 2009, 156: 826-841 
[28].Huang W, Wang Z G, Luo S B, Liu J. Parametric effects on the combustion flow field of a typical strut-based scramjet combustor. Chinese Science Bulletin, 2011, 56(35): 3871-3877

[29].Zhong F, Chen L, Li F, Zhang X, Sung C J. Numerical simulation of ignition and combustion of ethylene in a supersonic model combustor with a reduced kinetic mechanism. Combustion Science and Technology, 2013, 185: 548-563

[30]. Huang W, Wang Z G Li S B, Liu W D. Influences of $\mathrm{H} 2 \mathrm{O}$ mass fraction and chemical kinetics mechanism on the turbulent diffusion combustion of $\mathrm{H} 2-\mathrm{O} 2$ in supersonic flows. Acta Astronautica, 2012, 76: 51-59

[31].Marshall C B, Kurkov A P. Analytical and experimental study of supersonic combustion of hydrogen in a vitiated air stream. NASA TM X 2828, 1973

[32]. Huang W, Liu W D, Li S B, Xia Z X, Liu J, Wang Z G. Influences of the turbulence model and the slot width on the transverse slot injection flow field in supersonic flows. Acta Astronautica, 2012, 73: 1-9

[33].Pudsey A S, Boyce R R, Wheatley V. Influences of common modeling choices for high-speed transverse jet-interaction simulations. Journal of Propulsion and Power, 2013, 29(5): 1076-1086

[34]. Huang W, Wang Z G, Pourkashanian M, Ma L, Ingham D B, Luo S B, Lei J, Liu J. Numerical investigation on the shock wave transition in a three-dimensional scramjet isolator. Acta Astronautica, 2011, 68: $1669-1675$

[35]. Turner J C, Smart M K. Mode change characteristics of a three-dimensional scramjet at Mach 8. Journal of Propulsion and Power, 2013, 29(4): 982-990

[36].Segal C. The scramjet engine processes and characteristics. Cambridge University Press, 2009

[37].Huang W. Design exploration of three-dimensional transverse jet in a supersonic crossflow based on data mining and multi-objective design optimization approaches. International Journal of Hydrogen Energy, 2014, 39: 3914-3925 


\section{Figure captions}

Fig.1 Schematic diagram of a dual-mode combustor with backward-facing steps (unit: mm).

Fig.2 Comparison between the experimental data and the predicted results at the exit of the combustor under the combustion condition, (a) Mole fraction and (b) Mach number [30].

Fig.3 Static pressure contour comparison for different injection strategies, (a) $T_{1}+T_{2}$, (b) $T_{3}+T_{4}$ and (c) $T_{2}+T_{3}$.

Fig.4 Comparison of mass-weighted average Mach number distributions for different injection strategies.

Fig.5 Static pressure contour comparison for different fuel equivalence ratio arrangements, (a) Case 1, (b) Case

2, (c) Case 3, (d) Case 4, (e) Case 5 and (f) Case 6.

Fig.6 Comparison of mass-weighted average Mach number distributions for different fuel equivalence ratio arrangements.

Fig.7 Enlarged view of Mass-weighted average Mach number distributions for different fuel equivalence ratio arrangements.

Fig.8 Parametric contours and streamline distribution for Case 6, (a) Mach number, (b) Static temperature, (c)

$\mathrm{H}_{2}$ mole fraction, (d) $\mathrm{H}_{2} \mathrm{O}$ mole fraction, (e) Streamline distribution.

Fig.9 Mixing efficiency comparison for different injection strategies.

Fig.10 Mixing efficiency comparison for different fuel equivalence ratio arrangements. 


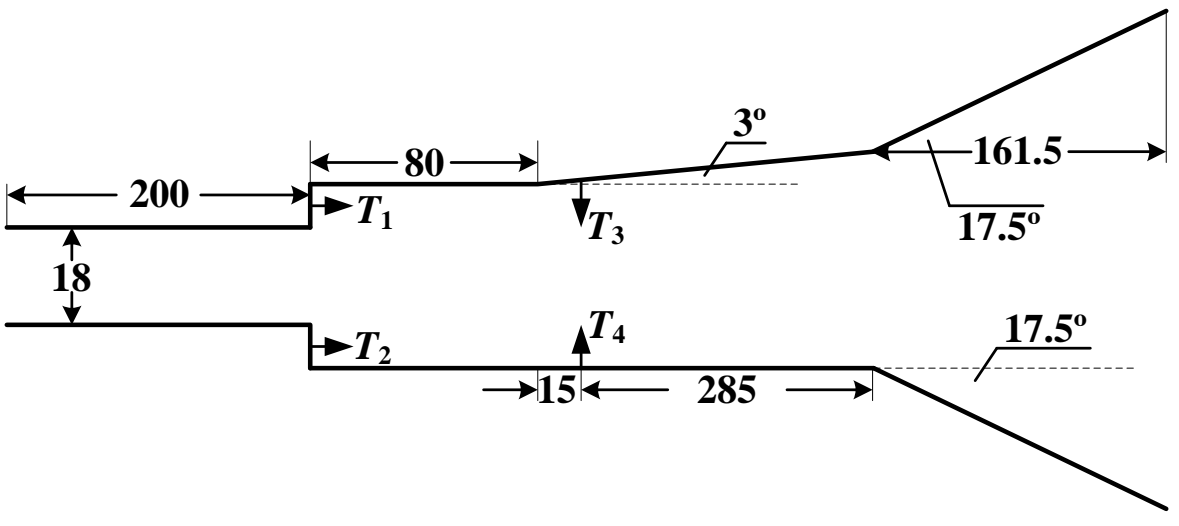

Fig.1 Schematic diagram of a dual-mode combustor with backward-facing steps (unit: mm). 


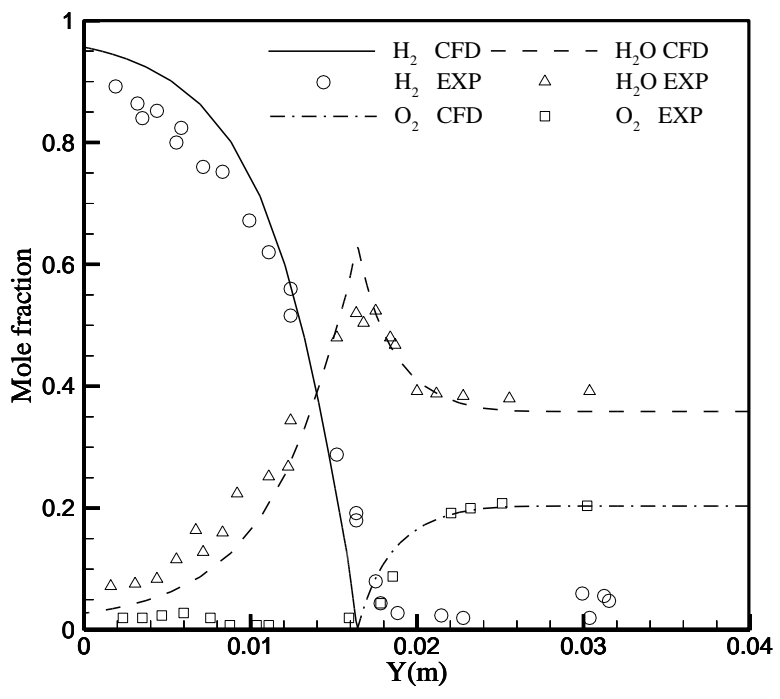

(a) Mole fraction

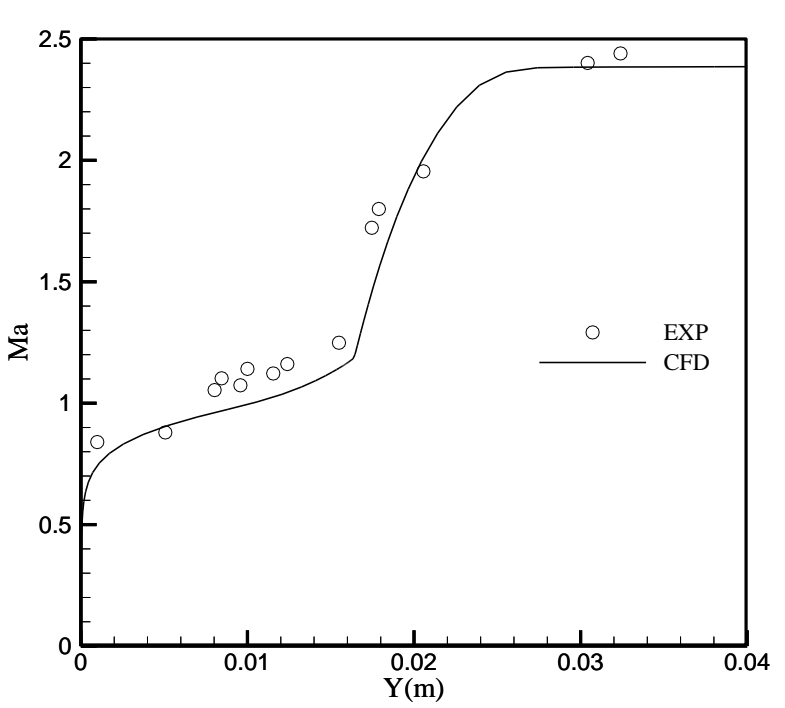

(b) Mach number

Fig.2 Comparison between the experimental data and the predicted results at the exit of the combustor under the combustion condition, (a) Mole fraction and (b) Mach number [30]. 


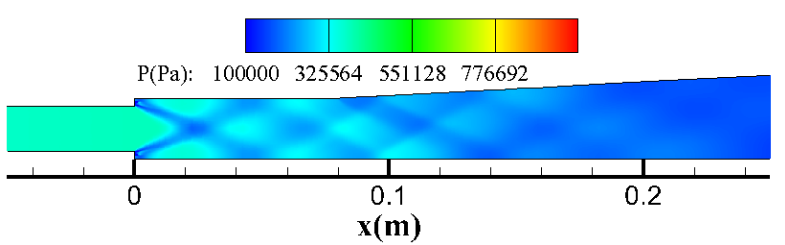

(a) $T_{1}+T_{2}$

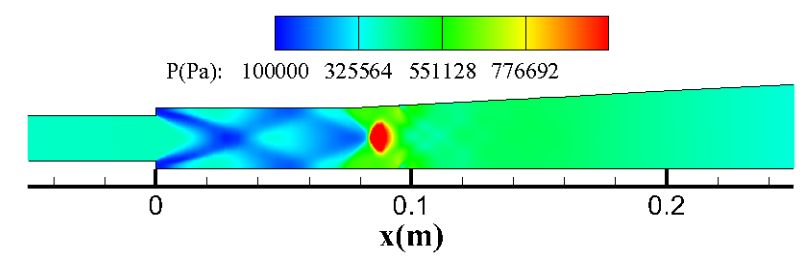

(b) $T_{3}+T_{4}$

$\mathrm{P}(\mathrm{Pa}): 100000325564551128776692$

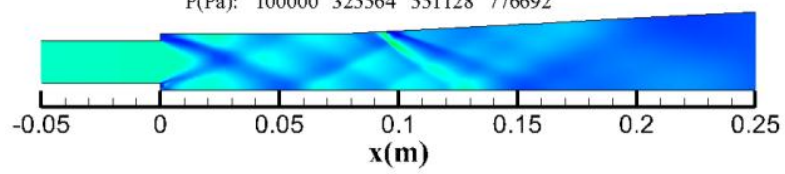

(c) $T_{2}+T_{3}$

Fig.3 Static pressure contour comparison for different injection strategies, (a) $T_{1}+T_{2}$, (b) $T_{3}+T_{4}$ and (c) $T_{2}+T_{3}$. 


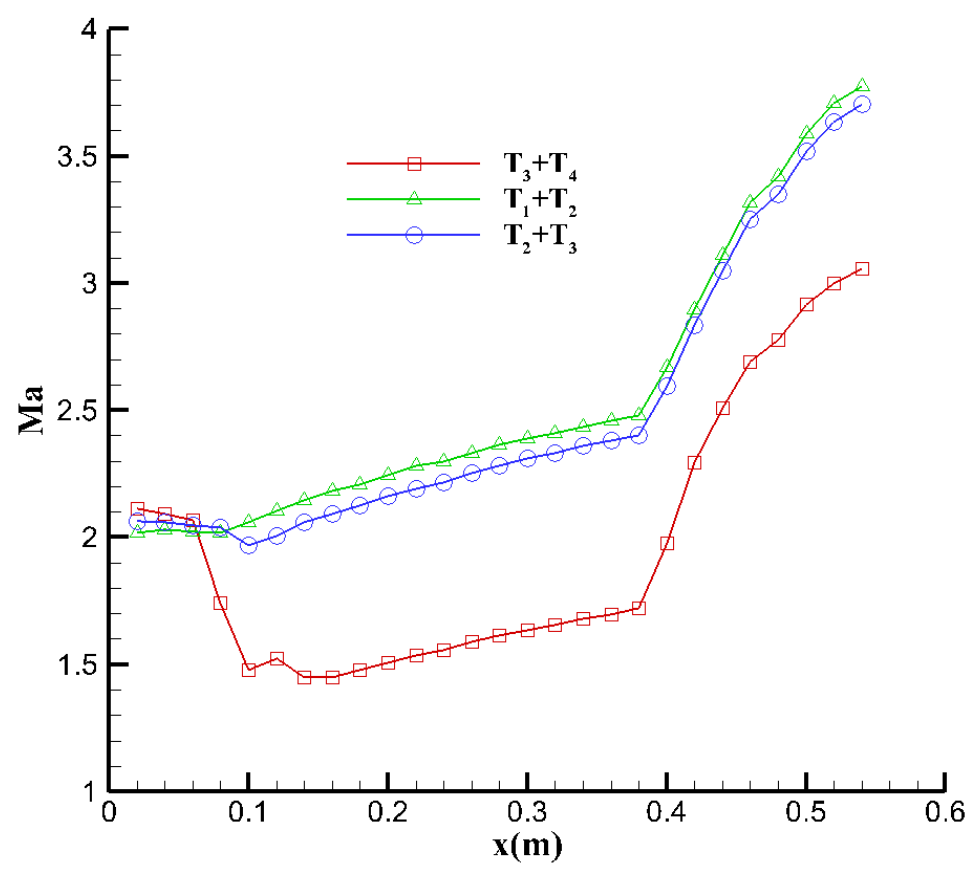

Fig.4 Comparison of mass-weighted average Mach number distributions for different injection strategies. 


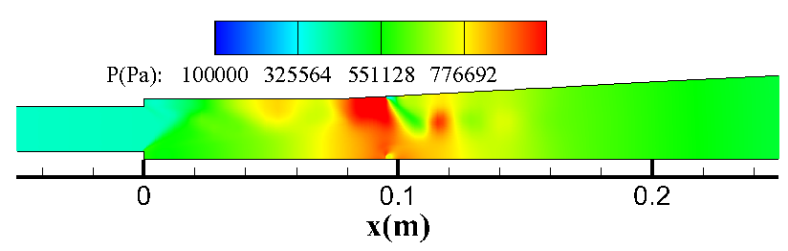

(a) Case 1

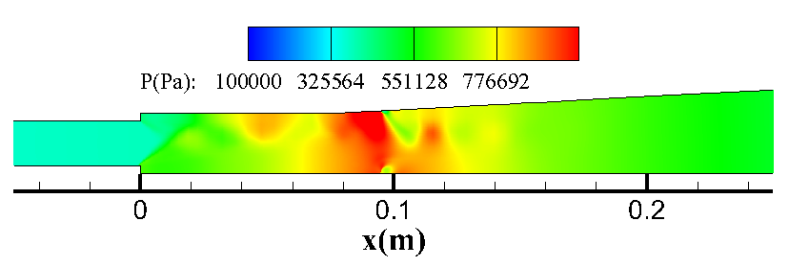

(c) Case 3

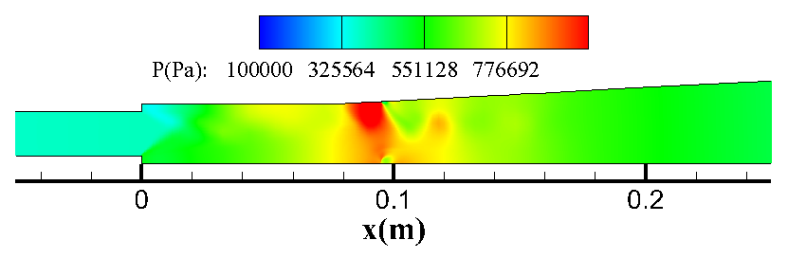

(e) Case 5

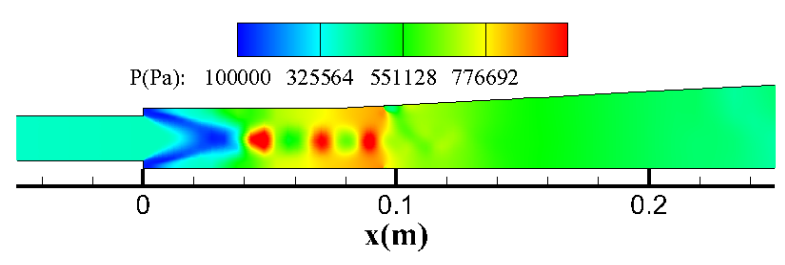

(b) Case 2

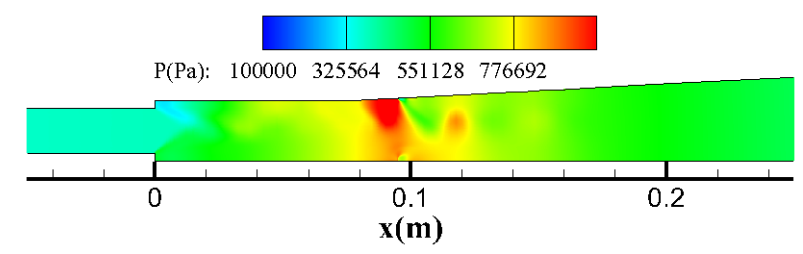

(d) Case 4

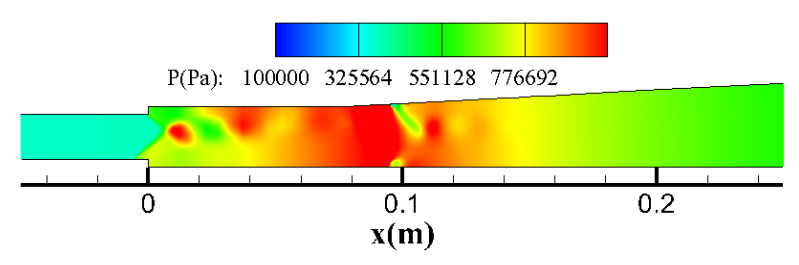

(f) Case 6

Fig.5 Static pressure contour comparison for different fuel equivalence ratio arrangements, (a) Case 1, (b) Case 2, (c) Case 3, (d) Case 4, (e) Case 5 and (f) Case 6. 


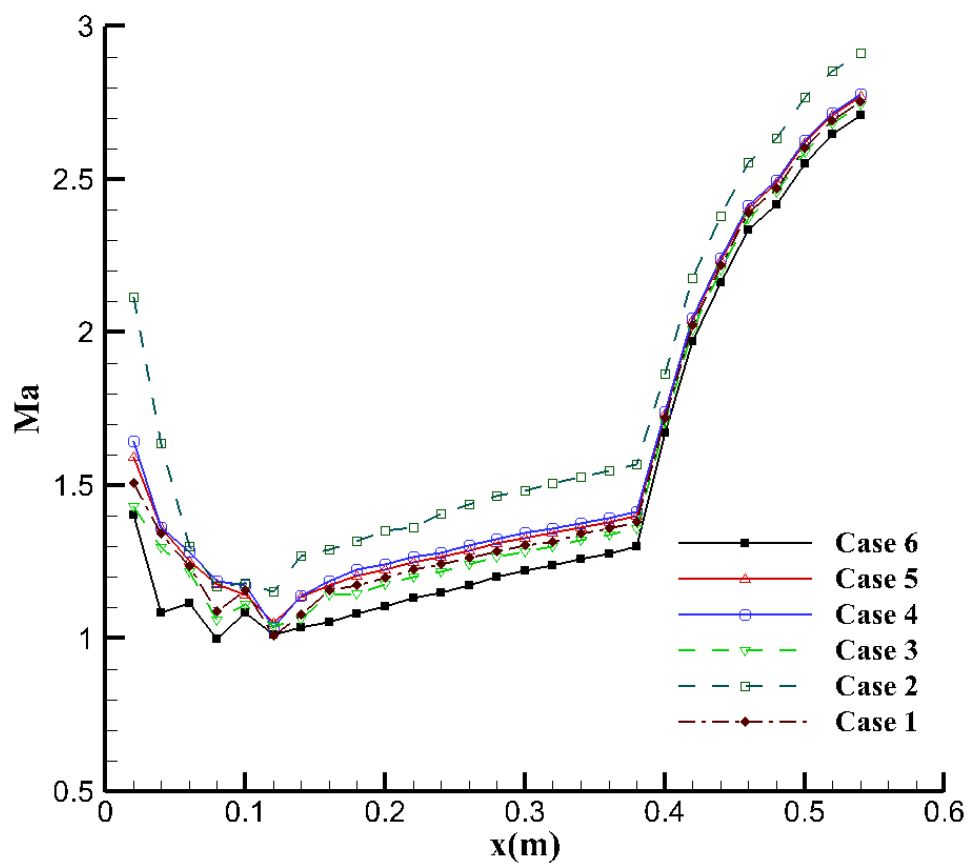

Fig.6 Comparison of mass-weighted average Mach number distributions for different fuel equivalence ratio arrangements. 


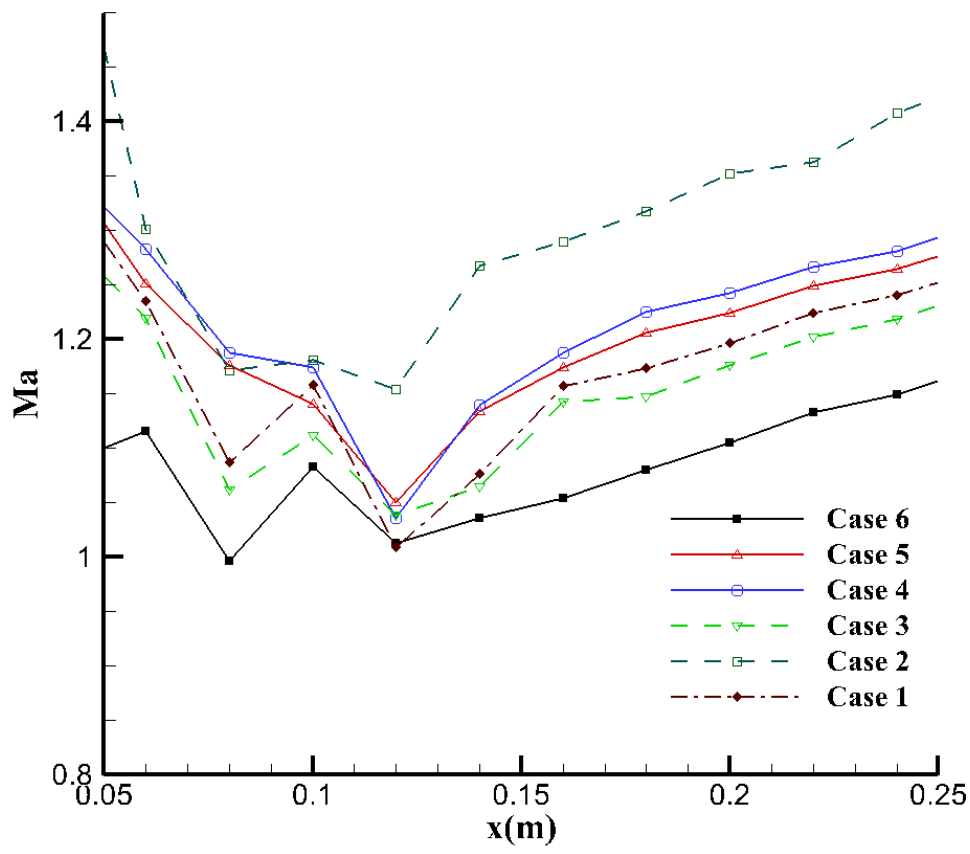

Fig.7 Enlarged view of Mass-weighted average Mach number distributions for different fuel equivalence ratio arrangements. 


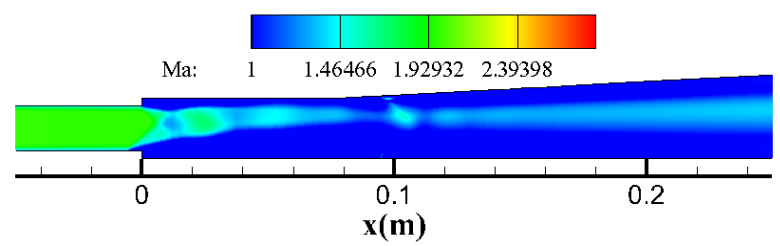

(a) Mach number

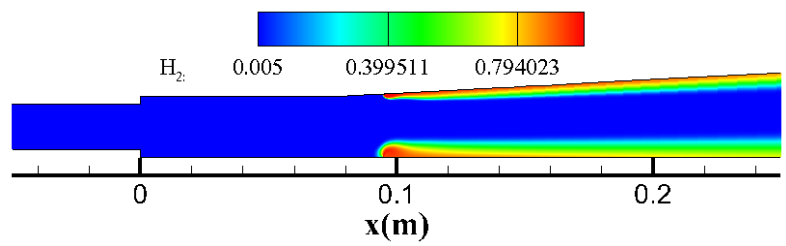

(c) $\mathrm{H}_{2}$ mole fraction

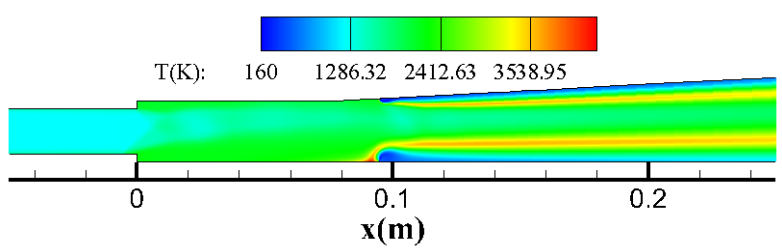

(b) Static temperature

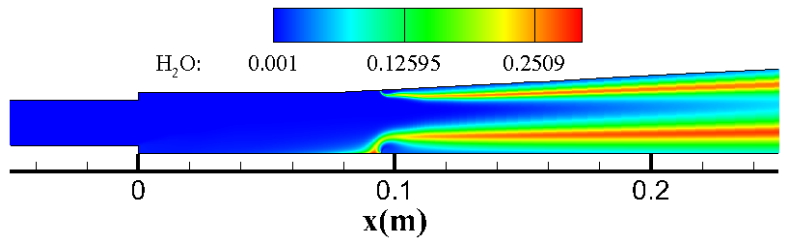

(d) $\mathrm{H}_{2} \mathrm{O}$ mole fraction

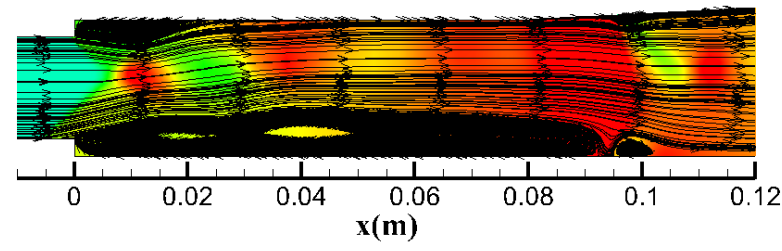

(e) Streamline distribution

Fig.8 Parametric contours and streamline distribution for Case 6, (a) Mach number, (b) Static temperature, (c) $\mathrm{H}_{2}$ mole fraction, (d) $\mathrm{H}_{2} \mathrm{O}$ mole fraction, (e) Streamline distribution. 


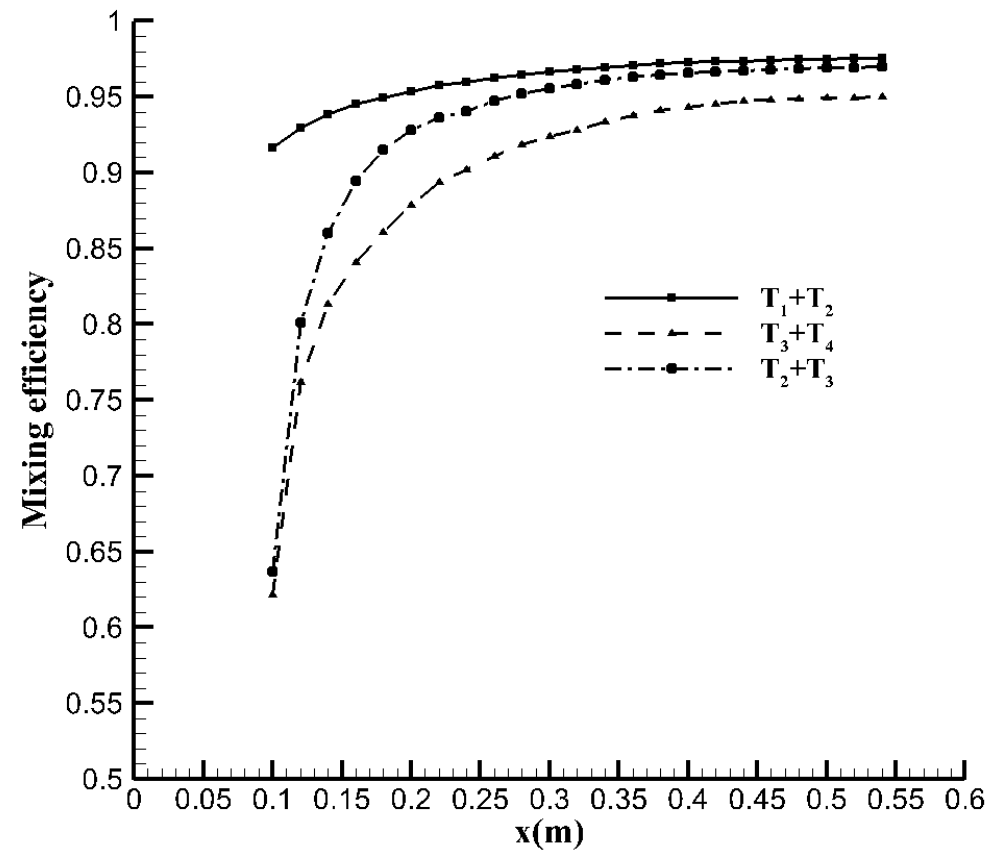

Fig.9 Mixing efficiency comparison for different injection strategies. 


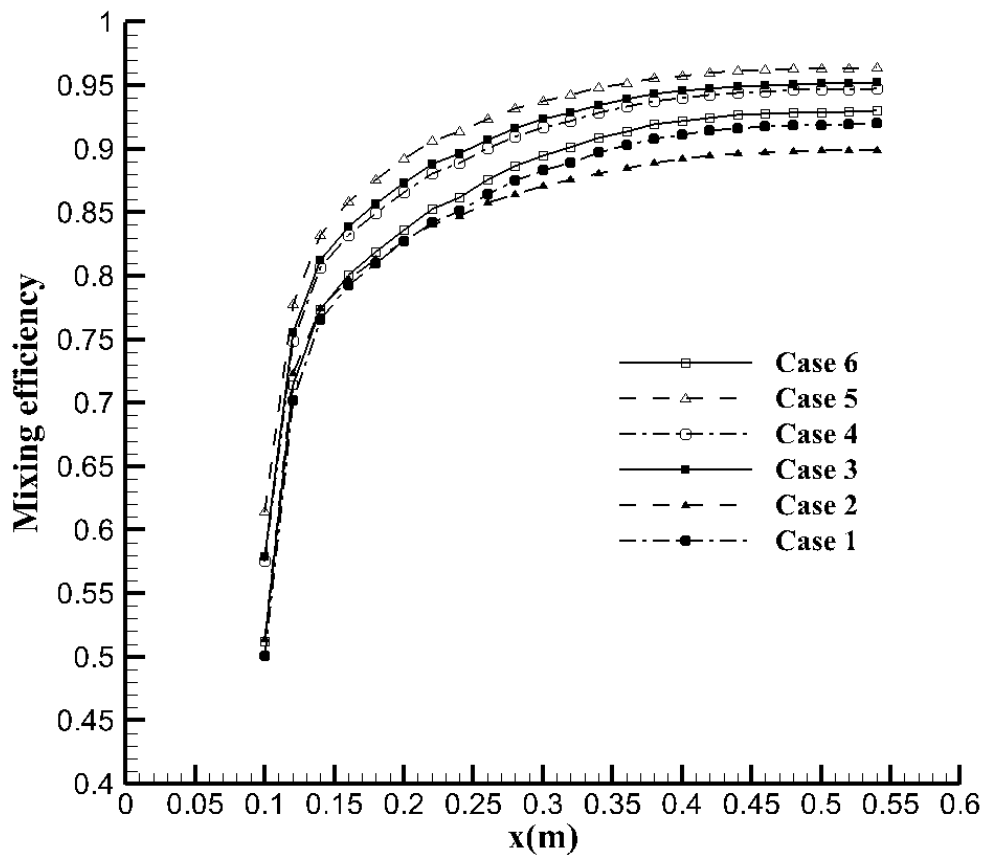

Fig.10 Mixing efficiency comparison for different fuel equivalence ratio arrangements. 
Table. 1 Arrangement of fuel equivalence ratio for $T_{3}$ and $T_{4}$.

\begin{tabular}{|l|c|c|c|c|c|c|}
\hline & Case 1 & Case 2 & Case 3 & Case 4 & Case 5 & Case 6 \\
\hline$T_{3}$ & 0.8 & 0.8 & 0.6 & 0.6 & 0.5 & 0.8 \\
\hline$T_{4}$ & 0.4 & 0.2 & 0.6 & 0.4 & 0.5 & 0.8 \\
\hline
\end{tabular}

